\title{
A Comparative Study for Performance of Five Landsat-based Vegetation Indices: Their Relations to Some Ecological and Terrain Variables
}

\author{
Ayad. M. Fadhil Al-Quraishi ${ }^{1 *}$, Hawar. A. S. Razvanchy ${ }^{2}$, Heman. A. A. Gaznayee ${ }^{3}$ \\ ${ }^{1}$ Surveying and Geomatics Engineering Department, Faculty of Engineering, Tishk International University, Erbil 44001, \\ Kurdistan Region, Iraq.Email: ayad.alquraishi@gmail.com \\ ${ }^{2}$ Dept. of Soil and Water Sciences, College of Agricultural Engineering Sciences, Salahaddin University-Erbil, Erbil 44003, \\ Kurdistan Region, Iraq.Email: hawar.sadiq@su.edu.krd \\ ${ }^{3}$ Department of Forestry, College of Agricultural Engineering Sciences, Salahaddin University-Erbil, Erbil 44003, Kurdistan \\ Region, Iraq. Email: heman.ahmed@su.edu.krd \\ "Correspondence: ayad.alquraishi@gmail.com
}

\begin{abstract}
Spectral vegetation indices and their relations to some ecological and terrain variables in the Iraqi Kurdistan Region (IKR) is the main objective of this study. A mosaic of two Landsat-7 ETM+ images was utilized to produce five spectral vegetation indices, and Terra ASTER Digital Elevation Model (DEM) dataset were employed. The Normalized Difference Vegetation Index (NDVI), Soil Adjusted Vegetation Index (SAVI), Optimized Soil Adjusted Vegetation Index (OSAVI), Tasseled Cap Greenness, Land Surface Temperature (LST) were utilized for this study. The results of the current study revealed that MSAVI2 is more reliable and accurate in depicting the vegetation presence in the IKR, which is occupied $34.7 \%$ of the total study area in 2014. In terms of terrain variables, all vegetation indices responded to variation of aspect ratio variation. It was found that the densest vegetation exists between 180 to $350^{\circ}$. Mainly, in the South $\left(157.5^{\circ}-202.5^{\circ}\right)$, Southwest $\left(202.5^{\circ}-247.5^{\circ}\right)$, West $\left(247.5^{\circ}-292.5^{\circ}\right)$, Northwest $\left(292.5^{\circ}-337.5^{\circ}\right)$, and North $\left(337.5^{\circ}-360^{\circ}\right)$. In contrast, from the aspect ratio point of view, vegetation cover growth was in its maximum status in the shaded side of the mountains, more than the sunny side. Additionally, the adequate slope for vegetation growth in the mountainous lands is 9-17\%. Statistically, the LST appeared negative relations with vegetation indices and elevation.
\end{abstract}

Keywords: Vegetation Indices, Landsat ETM+, GIS, Kurdistan, Iraq

Received: October $2^{\text {nd }}, 2020$ / Accepted: December $26^{\text {th }}, 2020$ / Online: January $2^{\text {nd }}, 2021$

\section{Introduction}

Geo-informatics is a modern discipline of sciences, which integrates acquisition, modeling, analysis, and management of spatially referenced data. Most of Geo-informatics are related to the use of Remote Sensing (RS), Geographical Information Systems (GIS), and Global Navigation Satellite System (GNSS) technologies (Gibson, 2000). The remote sensing has the advantage of providing a synoptic view and broad area coverage, which impart knowledge about conditions on the Earth's surface that change in the landscape over time (Gillies et al., 1997; Jensen, 1996). GIS allows various manipulations, including map measurers, map overlay transformation, geographic design, and database management (Chrisman, 20,2). 
The advancement of information records from satellites is a crucial prerequisite to improve our comprehension of characteristic and human-instigated changes on the Earth and their suggestions (NRC, 2007; Fadhil, 2009). Spectral vegetation indices have been utilized to check Earth's vegetative cover utilizing the reflection proportions of green vegetation. One of the significant applications for far off detecting data is the discovery and evaluation of green vegetation. Effectively photosynthesizing plants utilize blue and red light as vitality sources. Accordingly, they reflect a moderately modest quantity of these wavebands to the sensor (Gaznayee and Al-Quraishi 2019a; Al-Quraishi et al., 2020). Near-infrared vitality is profoundly reflected by the cell divider/air interface, which is essential for the inner structure of plants. The primary vegetative lists were direct proportions of these otherworldly groups, basically utilizing the (RED) and the near-infrared (NIR) bands. Throughout the long term, new vegetative list models have been intended to recognize scanty green vegetation, and all of them are limiting impacts of soil reflection splendor, geographical bending, and barometrical (Harris, 2004; Fadhil, 2013). Precise assessment of vegetation reaction over various year time scales is essential for worldwide change (Fadhil, 2009; Gaznayee and AlQuraishi, 2019a); Justice et al., 1998; Fadhil, 2011; Gaznayee and Al-Quraishi., 2020).

Studies that discussed the relationship between lightning and surface characteristics such as elevation, slope, and vegetation are quite limited (Kotroni and Lagouvardos, 2008). Dissing and Verbyla (2003) found a positive correlation between elevation and vegetation cover in their study in Alaska. Also, Kilinc and Beringer (2007) studied the relationship between elevation and vegetation density in the Northern Territory of Australia. Herrmann et al. (2016) studied the relationship between vegetation cover and ecosystems in different elevations. They found that vegetation cover responses to elevation variation in the wet and dry years, and a positive correlation between percentiles of annual NDVI and precipitation. The Studies for the relationship between elevation and ecology variables are widely available, especially investigating how different vegetation types change with climate change (Gitlin et al., 2006; Kelly \& Goulden, 2008; Crimmins et al., 2009 and 2010). High elevation increase in vegetation growth documented earlier in the European studies (Jolly et al. 2005; Leonelli et al. 2011). Few studies (Jolly et al., 2005; Piao et al., 2011; Al-Quraishi and Negm, 2020) have investigated the spatial patterns of elevation-dependent vegetation response to climate at a regional scale.

Currently, Iraq has become one of the most important agricultural products consumptive countries in the Middle East, mainly with wheat, rice, vegetables, and fruit. The Iraqi Kurdistan Region (IKR), the Northern territories of Mesopotamia, which consider as a fertile zone, has been under investigation by different researchers (Fadhil, 2009; Gaznayee and Al-Quraishi, 2019b; Al-Quraishi et al., 2019). Therefore, to encourage the local agricultural sectors, there is a need to pay attention to the land use planning and the available natural resources management. For those reasons, finding an accurate, reliable, and realistic vegetation cover index is essential to make a better decision and precisest area of fields. The tiniest variation in the real result of the vegetation cover should take into consideration. Many studies have been done to find the best vegetation index with much differentiation in the final results. The general goals of this study were to compare the performance of five spectral vegetation indices for detecting vegetation vitality and investigate their relations with some soil and topography variables. The investigated indices were; the Normalized Difference Vegetation Index (NDVI), Soil Adjusted Vegetation Index (SAVI), Optimized Soil Adjusted Vegetation Index (OSAVI), Second Modified Soil Adjusted Vegetation Index (MSAVI2), Tasseled Cap Greenness (TCG), and Land Surface Temperature (LST). Furthermore, the study aimed at stating the statistical relations among the vegetation covers and two ecological variables (rain amounts and land surface temperature), and three terrain variables (elevation, slope, and aspect ratio). 


\section{Materials and Methods}

\subsection{Location of the Study Area}

The study area (Figure 1) includes some parts of Erbil, Duhok, Sulaimaniyah governorates of the IKR, and Ninewa Governorate in the Northern part of Iraq. It comprises of 13 districts; Erbil, Shaqlawa, Makhmour, Soran, Akre, Shekhan, Amedi, Mergasor, Pshdar, Choman, Rania, Dokan, and Koya, which covers an area of $22,546.6 \mathrm{~km}^{2}$. The geographical position extends from latitudes $37^{\circ}: 22^{\prime}: 27^{\prime \prime}$ to $35^{\circ}: 26^{\prime}: 19^{\prime \prime} \mathrm{N}$, and longitudes $43^{\circ}: 02^{\prime}: 43^{\prime \prime}$ to $45^{\circ}: 23^{\prime}: 13^{\prime \prime} \mathrm{E}$.

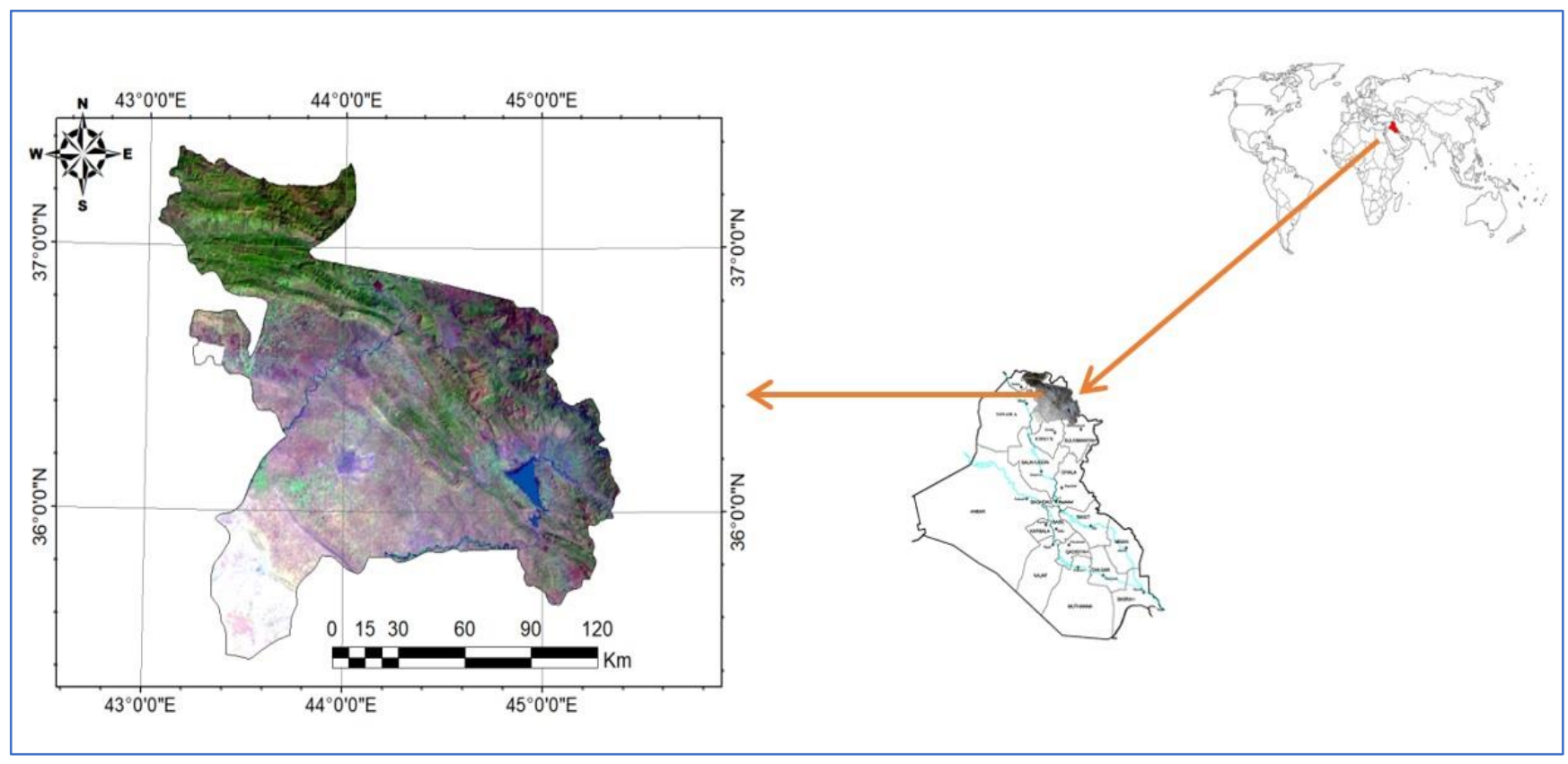

Figure 1. Map of the study area and its Landsat color composite (RGB 741) of 2012.

\subsection{Physiography of the Study Area}

The IKR is mostly a mountainous area, with the highest peak of 3,611.0 m, locally known as Cheekha Dar (black tent). The mountains of IKR are part of the Zagros Mountains series, which also extends in Iran, bordering the IKR from the East. Several rivers are flowing and running through the mountains of the region, making it distinguished by its fertile lands, plentiful water, and picturesque nature. The Great and the Little $\mathrm{Zab}$ rivers are flowing from the East to the West through the region, while the Tigris River enters Iraq from the IKR after flowing from Turkey (Anonymous, 2003). In the Western and Southern parts of the IKR, the area is not as mountainous as it is in the East, that it is rolling hills and sometimes plains that make up the area; however, it is greener than the other parts of Iraq. On the other side, Lake Dokan can be considered as the largest lake in the IKR. Besides, several smaller lakes in the region, such as Duhok and Darbandekhan lakes (Izady, 1992; Gaznayee and Al-Quraishi, 2020). The vegetated cover mostly consists of grasses flourishes during the winter and spring seasons, giving the whole region a green look. In summer, the vegetation dries up, and the climate becomes hot and dry (Anonymous, 2014). 


\subsection{Climate of the study area}

\subsubsection{Temperature}

Iraq, including its northern part, the IKR, is located in a semi-arid region, which is characterized by extreme conditions, that has large temperature differences between day and night, and winter and summer. In summer, the temperature reaches beyond $45{ }^{\circ} \mathrm{C}$ in the daytime at the Southern boundaries of the IKR, while in the Northern edges, it goes down well below $20{ }^{\circ} \mathrm{C}$ at night. In the winter, daily temperature ranges from about $(-15){ }^{\circ} \mathrm{C}$ to about $15^{\circ} \mathrm{C}$. Accordingly, climate of the study area is classified as semi-arid continental. In other words, hot and dry in summer and cold and wet in winter. The spring and autumn are short in comparison to summer and winter (Aziz, 2003). Therefore, more temperature variation is noted among the different weather station locations (Table 1).

Table 1. The monthly air temperature averages for the year (2012).

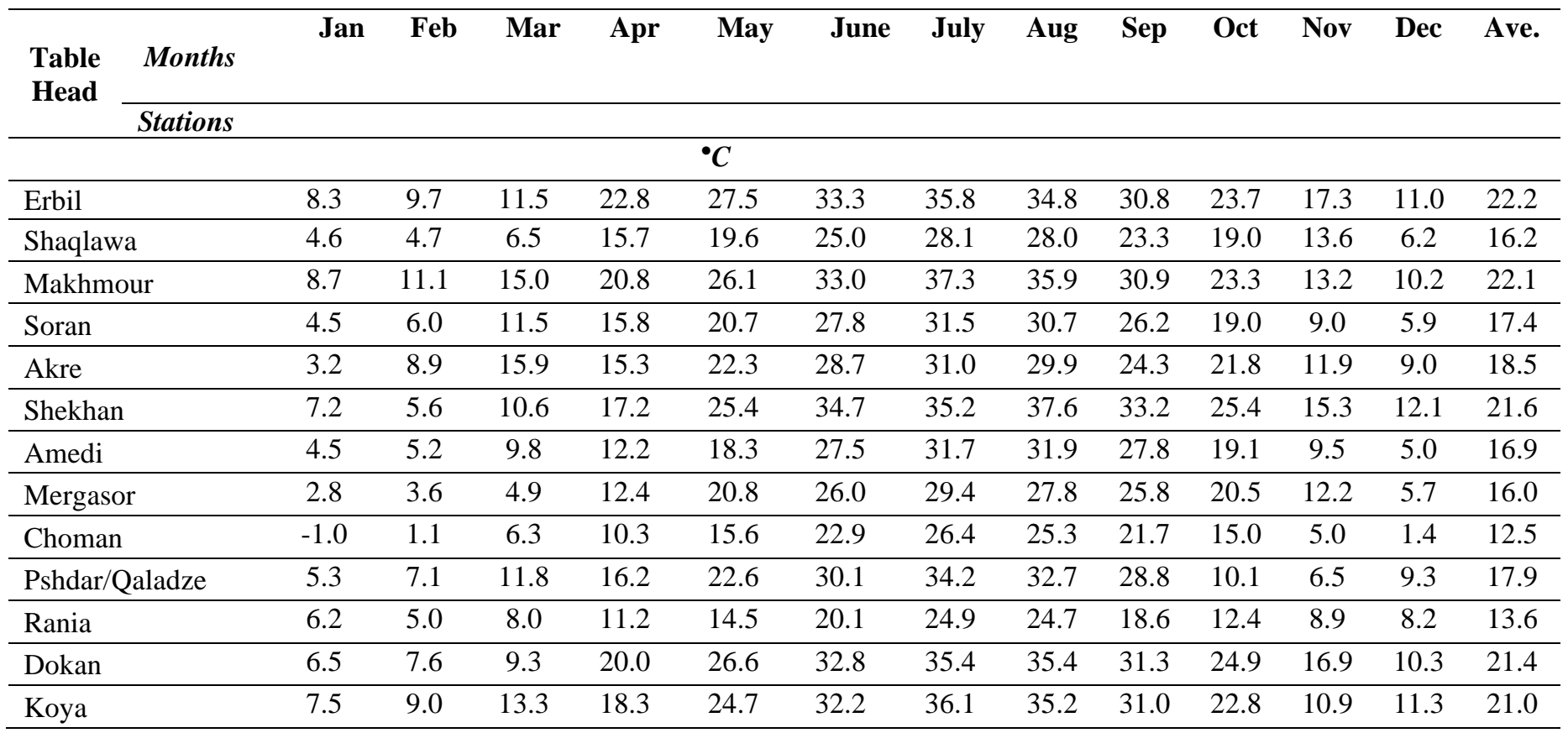

\subsubsection{Rainfall}

Generally, the rainfall begins from September to June, and it increases from the Southwest toward the Northeast direction. The annual rain average starts from $250 \mathrm{~mm}$ in the South of the Erbil area to more than 1,200 $\mathrm{mm}$ in the high mountains bordering Iran in the Northeast and Turkey in the North (Aziz, 2003; Fadhil, 2011; Gaznayee and Al-Quraishi, 2019a). Table 2 shows the monthly rainfall amounts during the hydrological year (2011- 2012); however, there is no rainfall in July and August of each year in Iraq, including the IKR.

\subsection{Digital Image Processing (DIP)}

\subsubsection{Remotely Sensed Dataset and Preprocessing}

Two scenes (path/row: 169/35 and 170/34) of Landsat-7 Enhanced Thematic Mapper Plus (TM+) acquired on 7/08/2012 and 14/08/2012 were downloaded from the www.glovis.usgs.gov. A spatial resolution of $30 \mathrm{~m}$ 
characterizes the images and they are free of clouds and high quality. Terra ASTER Digital Elevation Model (DEM) also has been downloaded to extract the slope, TIN, and aspect information. Preprocessing for Landsat-7 ETM+ and the DEM datasets have been done, including the geometric and radiometric calibration as a first step. The second step was the correcting of the SLC-off (scan line corrector-off) dataset of the ETM+ using a gap-filling technique with the aid of ENVI Ver. 5.3. The conversion of the DN values to reflectance values using a module in ENVI software has been achieved. A mosaic of the two ETM+ scenes was then produced utilizing the ERDAS Imagine software platform.

Table 2. The monthly and total rain amounts in the study area for the hydrological year (2011-2012).

\begin{tabular}{|c|c|c|c|c|c|c|c|c|c|c|c|}
\hline Months & Sep & Oct & Nov & Dec & Jan & Feb & Mar & Apr & May & Jun & \multirow[t]{2}{*}{ Sum } \\
\hline Stations & & & & & & & & & & & \\
\hline & & & & & $C^{\circ}$ & & & & & & \\
\hline Erbil & 0.0 & 8.4 & 8.7 & 22.0 & 37.4 & 30.9 & 60.4 & 9.6 & 11.7 & 0.0 & 189.1 \\
\hline Shaqlawa & 0.0 & 14.0 & 28.0 & 33.5 & 106.0 & 87.5 & 167.0 & 34.5 & 12.0 & 0.0 & 482.5 \\
\hline Makhmour & 3.2 & 10.6 & 8.3 & 17.7 & 25.3 & 20.4 & 26.5 & 8.0 & 3.3 & 0.0 & 123.3 \\
\hline Soran & 5.2 & 13.4 & 43.2 & 51.3 & 89.4 & 81.5 & 108.3 & 51.2 & 17.1 & 0.0 & 460.6 \\
\hline Akre & 1.5 & 6.8 & 40.1 & 25.4 & 114.8 & 83.6 & 99.7 & 12.4 & 0.5 & 0.0 & 384.8 \\
\hline Shekhan & 0.0 & 4.0 & 16.0 & 18.0 & 109.0 & 55.0 & 120.5 & 9.0 & 0.0 & 0.0 & 340.5 \\
\hline Amedi & 29.0 & 48.0 & 66.0 & 52.0 & 83.0 & 98.0 & 81.0 & 86.0 & 3.0 & 0.0 & 546.0 \\
\hline Mergasor & 4.0 & 6.7 & 60.1 & 108.8 & 229.1 & 271.9 & 244.2 & 101.4 & 24.0 & 0.0 & $1,050.2$ \\
\hline Choman & 1.0 & 29.7 & 45.9 & 35.4 & 94.6 & 102.2 & 158.5 & 55.8 & 11.4 & 0.0 & 534.5 \\
\hline Pshdar/Qaladze & 0.0 & 28.5 & 39.5 & 45.5 & 126.5 & 143.0 & 209.0 & 36.0 & 7.0 & 0.0 & 635.0 \\
\hline Rania & 0.0 & 21.0 & 30.5 & 54.8 & 114.2 & 105.5 & 164.6 & 31.3 & 17.8 & 0.0 & 539.7 \\
\hline Dokan & 0.2 & 19.2 & 32.4 & 33.1 & 121.5 & 71.6 & 109.6 & 29.0 & 4.7 & 0.0 & 421.3 \\
\hline Koya & 0.0 & 12.5 & 14.5 & 46.5 & 158.3 & 76.0 & 122.2 & 32.0 & 8.0 & 0.0 & 470.0 \\
\hline
\end{tabular}

\subsubsection{Vegetation Indices}

The vegetation spectral indices were derived from the ETM+ images to highlight and state the vegetated cover in the study area, employing the ERDAS ERMapper software. The Normalized Difference Vegetation Index (NDVI), Optimized Soil Adjusted Vegetation Index (OSAVI), Second Modified soil adjusted vegetation index (MSAVI2), Tasseled Cap Greenness (TCG), and Land Surface Temperature (LST) were used in this study as spectral vegetation indices. ArcGIS software platform has been utilized for processing and classifying the resultant indices into three classes layers with a Natural Breaks (Jencks) classification method according to vegetation cover density. The area of each class was determined using the ERMapper. Then, using ERDAS Imagine 2014, the pixel reflectance values of all vegetation indices images were picked up for well-distributed forty different sites to calculate their statistical relations with the other study variables.

\subsubsection{NDVI}

The NDVI is calculated using the two bands Red (R) and Near Infrared band (NIR) of the Landsat ETM+ image. Rouse et al. (1973) was the first researcher who suggested this index.

$$
\mathrm{NDVI}=(\mathrm{NIR}-\mathrm{R}) /(\mathrm{NIR}+\mathrm{R})
$$


whereas;

$\mathrm{NIR}=$ the reflectance of Near-Infrared band $(760-900) \mathrm{nm}$.

Red $=$ the reflectance of Red band (630-690)nm.

\subsubsection{SAVI}

Huete (1988) proposed the SAVI, which is a hybrid between the NDVI and the Perpendicular Vegetation Index (PVI). It can calculate using Eq. 2:

$$
\mathrm{SAVI}=[(\mathrm{NIR}-\mathrm{R}) /(\mathrm{NIR}+\mathrm{R}+\mathrm{L})]^{*}(1+\mathrm{L})
$$

where:

$\mathrm{NIR}=$ the reflectance of Near-Infrared band $(760-900) \mathrm{nm}$.

$\mathrm{R}=$ the reflectance of Red band (630 - 690)nm.

$\mathrm{L}=$ constant.

$\mathrm{L}$ is a correction factor, and its value is dependent on the vegetation cover, varying from 0 (close canopy cover) to 1 (open canopy cover). For characterizing the different facies, the SAVI image was generated using $\mathrm{L}$ values of $0.25,0.5$, and 0.75 . Historically, SAVI is the term used when L is set to 0.5 (Huete, 1988). Also, Huete (1988) suggested that the value of 0.5 can be used when vegetation cover is unknown, as 0.5 represents intermediate vegetation cover. In this study, the $\mathrm{L}$ value of $(0.5)$ has been used.

\subsubsection{OSAVI}

The OSAVI was suggested by Rondeaux et al. (1996). The OSAVI was incorporated to reduce the background effect, which was confirmed by (Haboudane et al., 2002). OSAVI is the same as SAVI, with an adjustment factor of 0.16 .

$$
\text { OSAVI }=[(\mathrm{NIR}-\mathrm{R}) /(\mathrm{NIR}+\mathrm{R}+\mathrm{L})] *(1+\mathrm{L})
$$

whereas;

$\mathrm{NIR}=$ the reflectance of Near-Infrared band $(760-900) \mathrm{nm}$.

$\mathrm{R}=$ the reflectance of Red band (630 - 690)nm.

$\mathrm{L}=0.16$ (adjustment factor).

\subsubsection{MSAVI2}

The Modified Soil Adjusted Vegetation Index (MSAVI) and its later revision MSAVI2 are soil adjusted vegetation indices that seek to address some of the limitations of NDVI when applied to areas with a high degree of exposed soil surface. Also, it was designed to reduce the influence of soil in the image and to enhance the spectral sensitivity for concentrated vegetation cover.

$$
\operatorname{MSAVI} 2=(0.5)^{*}\left\{2 *(\mathrm{NIR}+1)-\operatorname{sqrt}\left[(2 * \mathrm{NIR}+1)^{\wedge} 2-8 *(\mathrm{NIR}-\mathrm{R})\right]\right\}
$$

whereas; 
$\mathrm{NIR}=$ the reflectance of Near-Infrared band $(760-900) \mathrm{nm}$.

$\mathrm{R}=$ the reflectance of Red band (630 - 690)nm.

The problem with the original soil-adjusted vegetation index (SAVI) is that it required specifying the soilbrightness correction factor (L) through trial-and-error based on the amount of vegetation in the study area. Qi et al. (1994a) developed the MSAVI, and later the MSAVI2 (Qi et al., 1994b) to more reliably and simply calculate a soil brightness correction factor.

\subsubsection{TCG}

The TCG is one of the Tasseled Cap Transformation (TCT) indicators, which were initially defined by (Kauth \& Thomas, 1976). It was applied according to Eq. 5, and it can be utilized to map the vegetation status in the studied area.

$$
\mathrm{TCG}=\mathrm{B} 1 *_{-}-0.2848+\mathrm{B} 2 *-0.2435+\mathrm{B} 3 *_{-} 0.5436+\mathrm{B} 4 * 0.7243+\mathrm{B} 5 * 0.0840+\mathrm{B} 7 *_{-}-0.1800
$$

whereas;

$\mathrm{B} 1=\mathrm{Blue}, \mathrm{B} 2=$ Green, B3= Red, B4= NIR, B5=SWIR1, and B7=SWIR2

\subsubsection{Soil Indices}

\subsubsection{LST}

The LST is one of the most important environmental parameters used in determining the exchange of energy and matter between the surface of the Earth and the lower layer of the atmosphere (Mohan, 2000). The source of thermal information was the thermal infrared band (band six of ETM+ dataset). The temperature transformation of the thermal infrared band into the value of ground temperature is done used the following equations mentioned in YCEO (2010):

$$
\begin{aligned}
& \text { DN to Radiance }=0.05518 *(\mathrm{i} 1)+1.2378 \\
& \text { Radiance to Kelvin }=1260.56 / \log ((666.09 / \mathrm{i} 1)+1) \\
& \text { Kelvin to Celsius }=\mathrm{i} 1-273.15
\end{aligned}
$$

whereas;

i1 $=$ Reflectance value of the thermal infrared band (band $6^{\text {th }}$ of Landsat 7 ETM+ image).

\section{$2.5 \mathrm{DEM}$}

The DEM raster dataset of the study area was used to extract the elevation values of each of the forty sites with the aid of ERDAS Imagine platform. On the other hand, the DEM was processed and analyzed using the ArcGIS 10.3 to produce the maps of the Aspect ratio, TIN, Slope, and Elevation contour.

\subsection{Statistical Analyses}

\subsubsection{Correlation Coefficient ( $r$ )}


The correlation coefficients (r) were calculated to find the strength of the statistical relations among all investigated indices, and the DEM-based derived indicators values. For this purpose, the Bivariate Correlations (Pearson Correlation Coefficient) was adopted to find which variables are statistically related to each other. To find the values of the vegetation maps and other variables in certain places inside the study area to be representative, forty sites (points) have been selected to pick the values of all studied variables (vegetation indices, ecological, and terrain indicators). It is vital to measure how those two variables (vegetation and terrain variation) simultaneously change together (Babbie, 2009).

\section{Results}

\subsection{Spectral Indices}

\subsubsection{Soil Indices}

3.1.1.1. LST

The LST map (Figure 2) revealed that the temperature tends to increase from the Northeast toward the Southeast. Whereas the mountainous area is characterized by lower surface temperature, then temperature begins to increase wherever moving toward the plains area gradually. Thus, an increase in land elevation results in a decrease in the LST. Also, the vegetative cover had a lower temperature than bare soil. Figure 2 shows that the Southern part of the study area's LST map (appeared in orange) had surface temperature ranged between $50-54^{\circ} \mathrm{C}$, which is lower than the LST of the middle part (appeared in red) of the IKR. In contrast, the surface temperature ranged between $54-58{ }^{\circ} \mathrm{C}$. Generally, the differences in the temperature because of the variation of the elevation. As mentioned above, the surface temperature is decreasing toward the Southeast due to the elevation decreasing, but, in the South part of the study area, more accurately in Makhmoor district, it appears that this area has a lower temperature, although it has a lower elevation. This is due to that area contain a high amount of Calcite $\left(\mathrm{CaCO}_{3}\right)$ in the soil and enormous numbers of Calcite mines comparing to the other parts. Furthermore, the soil colors of that area trending to be brighter in most places. Therefore, the reflectance increase, then the temperature decreases (Al-Quraishi et al., 2019). Statistically, the LST had significant negative correlations with the all studied vegetation indices and DEM in this study.

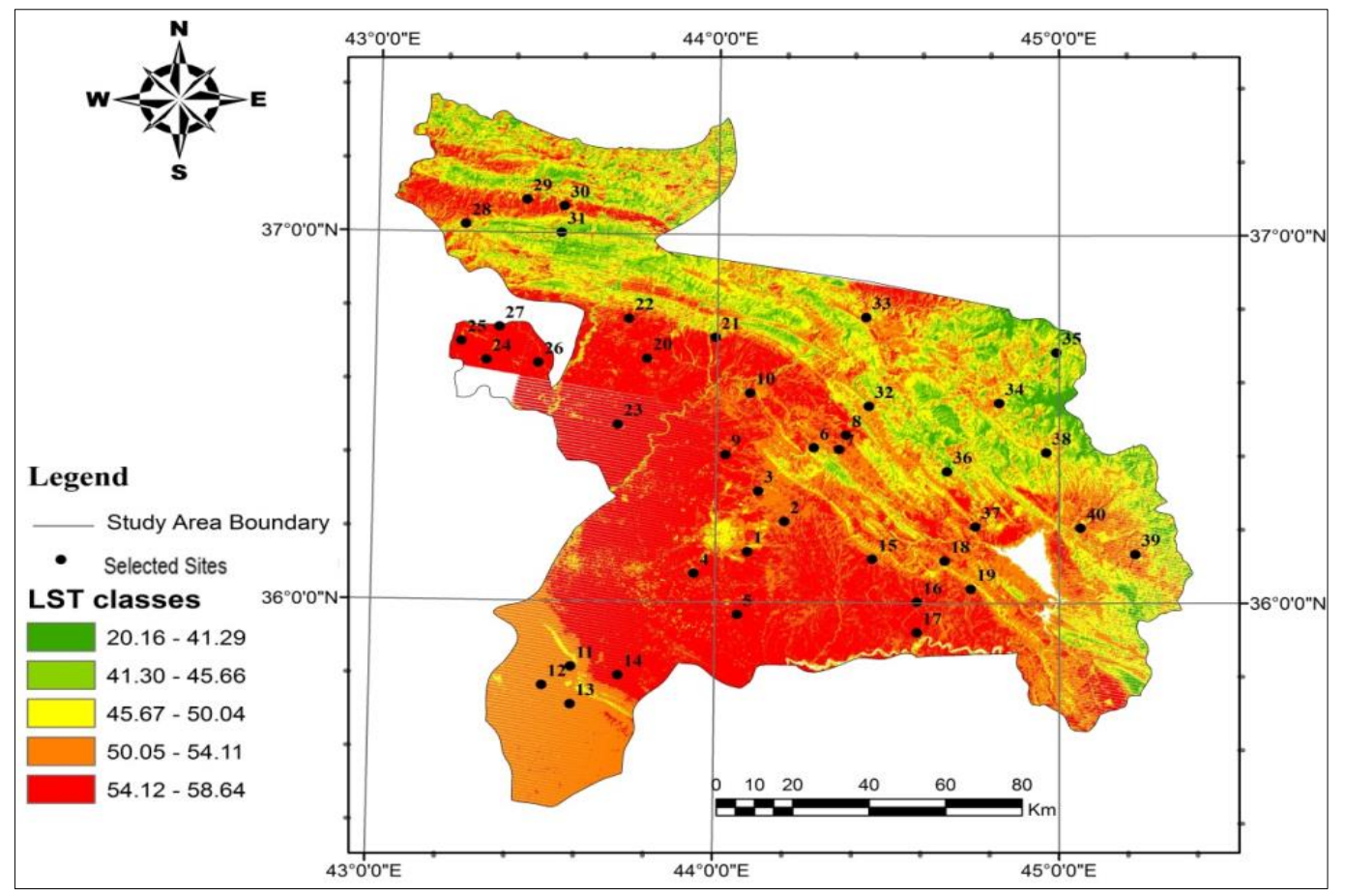

Figure 2. The LST classes map of the study area for the year 2012. 


\subsubsection{Vegetation Indices}

Five vegetation indices were achieved and employed to depict the spatial distribution of the vegetated cover. This study aimed to compare and investigate which of the five spectral indices is the most reliable and more accurate to be efficiently used for mapping and stating the vegetative cover vitality across the study area.

\subsubsection{NDVI}

The NDVI is used to investigate the vegetation cover health in the study area. Its result is presented in Figure 3 and Table 3, whereas the area of the vegetation covers was $8,079.9 \mathrm{~km}^{2}$, accounting for $35.8 \%$ of the entire study area. The spatial distribution of the NDVI-based vegetative cover appeared the densest vegetation level has existed in the Northwestern part, which contains a fluctuated mountainous area with high elevation, gradually decreasing toward the Southeast while sharply dropping toward the South.

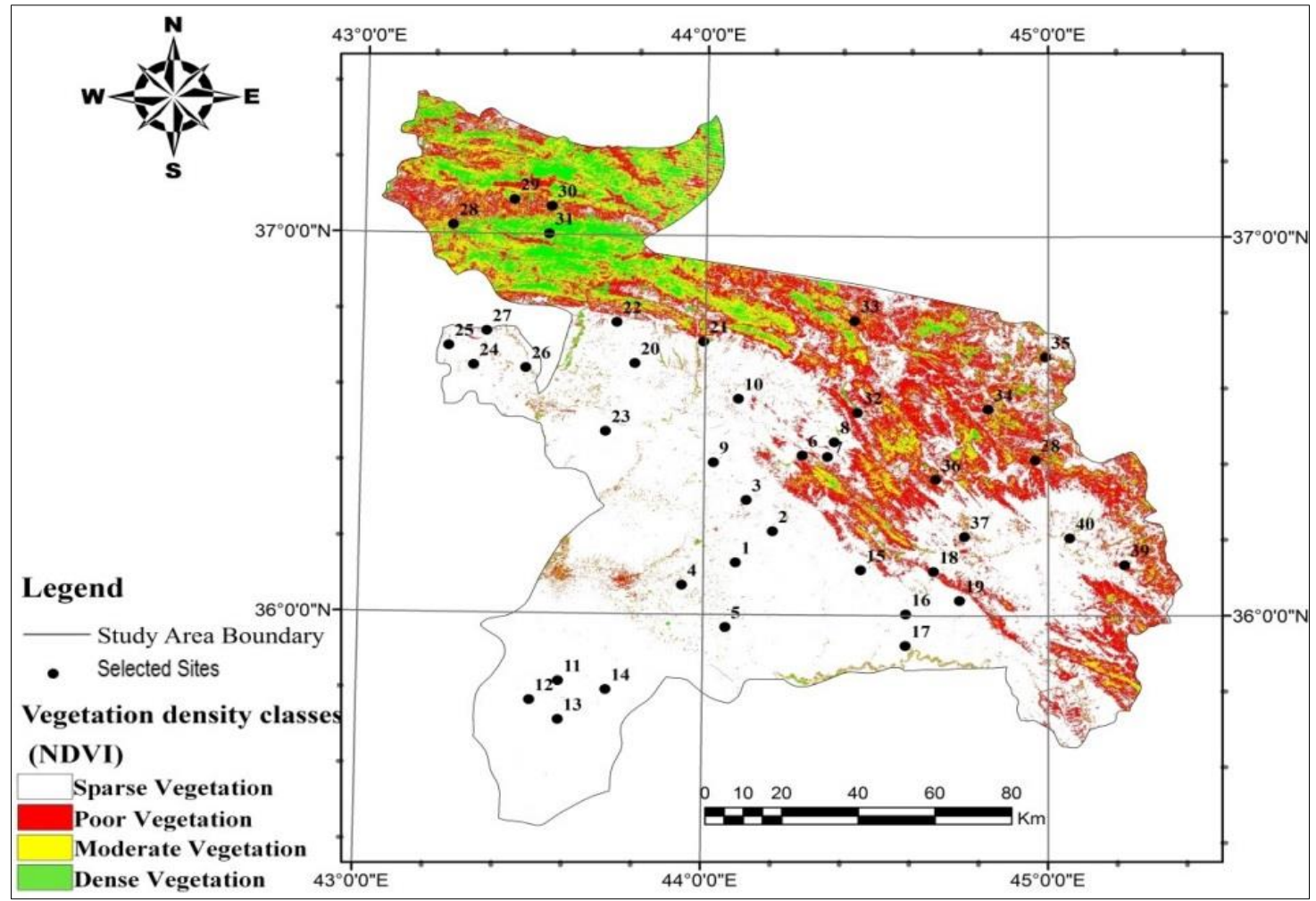

Figure 3. The NDVI-based vegetation cover density classes in the study area.

\subsubsection{SAVI}

The SAVI-based vegetation map is presented in Tigure 4. It showed that the vegetation cover in 2012 was $3,247.1 \mathrm{~km}^{2}$, accounting (14.4\%) of the entire study area. The area of each class was determined, as shown in Table 3. The results also revealed that the vegetation cover's area detected by SAVI is lower than that detected by the other vegetation indices. SAVI depicted more dense vegetated area in the Northwest part and less in the South and Southeast parts of the IKR. 


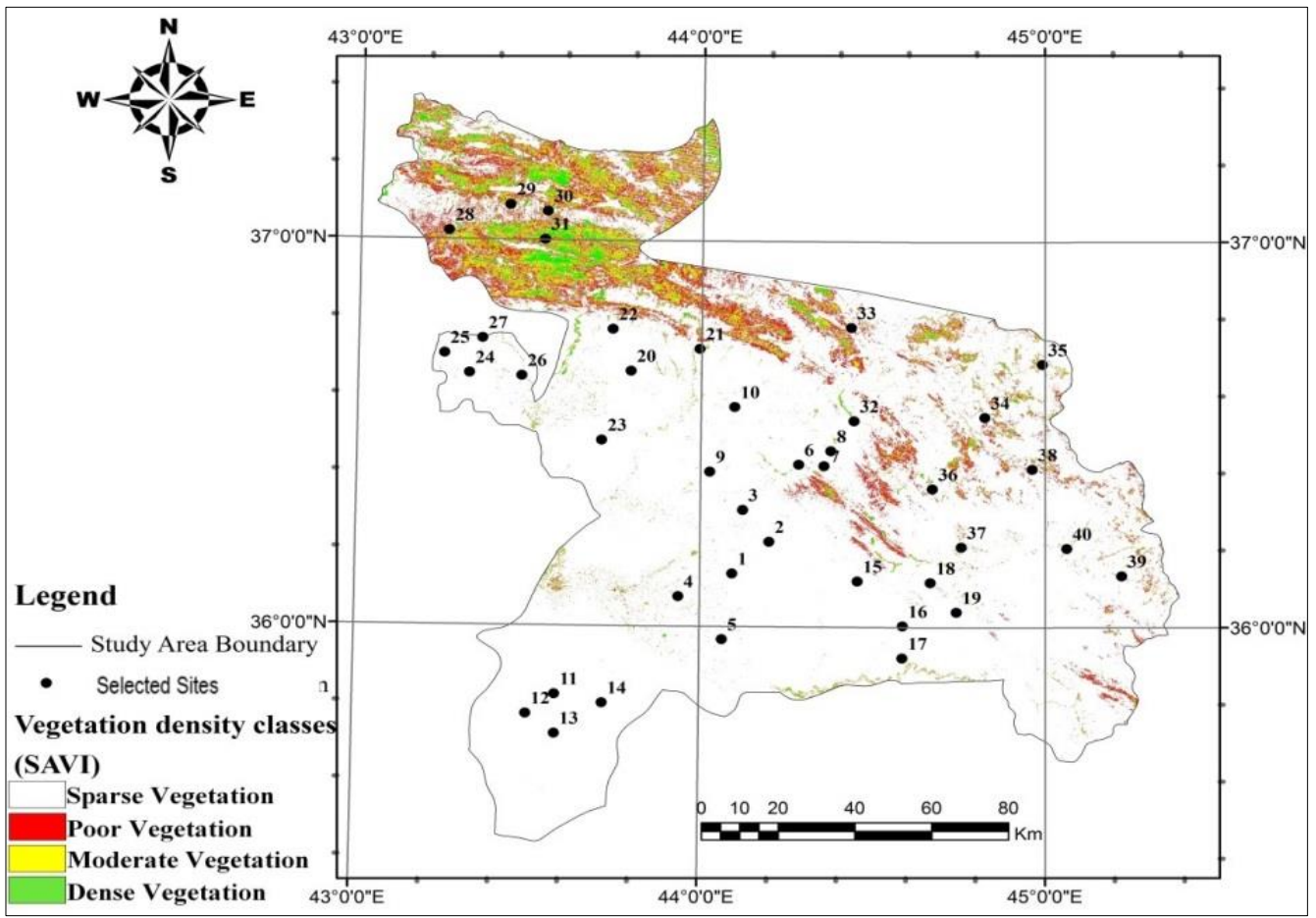

Figure 4. The SAVI-based vegetation cover density classes in the study area.

\subsubsection{OSAVI}

The OSAVI map (Tigure 5) showed that the vegetation cover area was 9,296.7 $\mathrm{km}^{2}$, accounting (41.2\%) of the total study area. Area of each class was computed and presented in Table 3. Results of the OSAVI-based vegetation cover is the highest one in terms of area of vegetation cover. The spatial distribution of OSAVIbased vegetation cover is very close to that of NDVI, with some variations in the dense vegetation cover in the edge of the study area located in the Southeast parts.

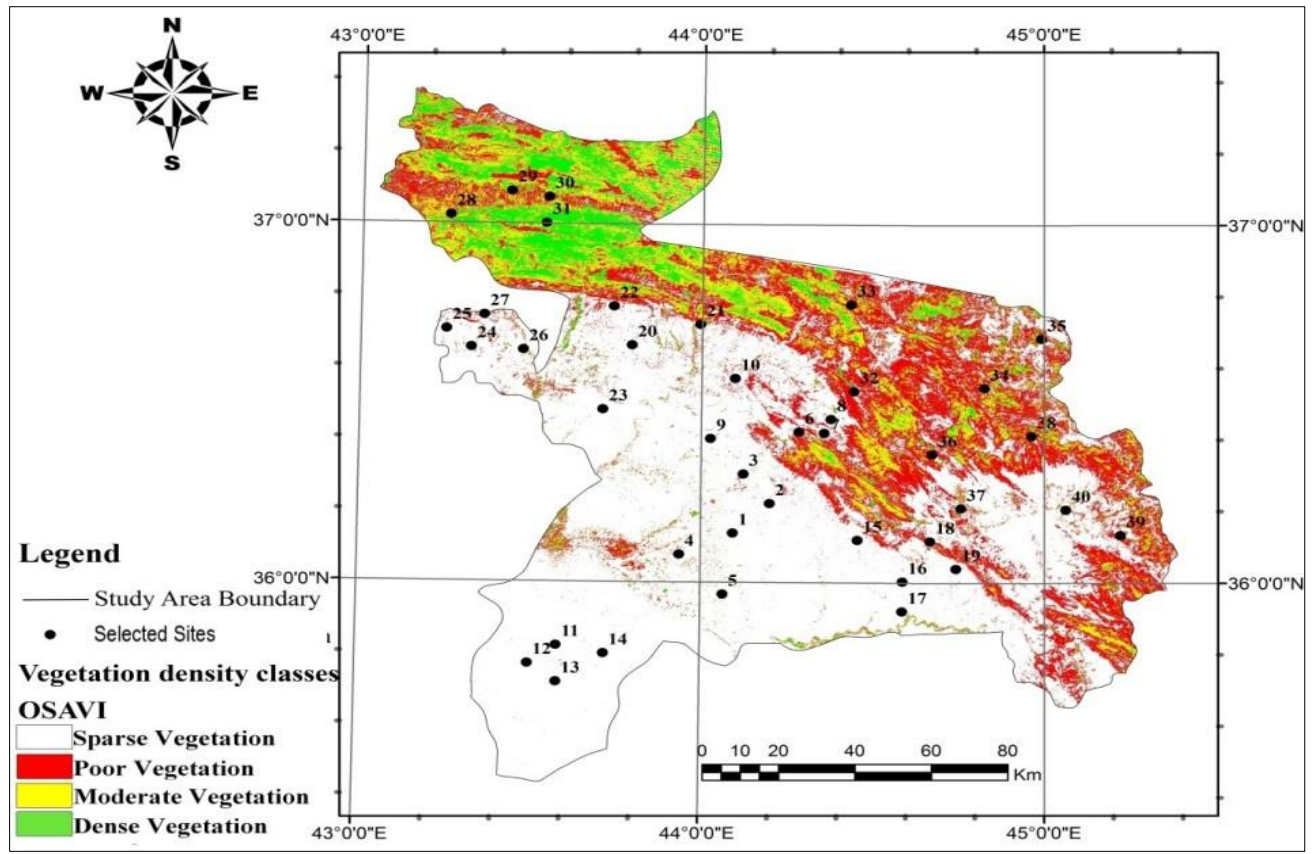

Figure 5. The OSAVI-based vegetation cover density classes in the study area. 


\subsubsection{MSAVI2}

MSAVI2 is another vegetation index produced using ERDAS platform, while ArcGIS is used to produce its map (Figure 6) as the other maps in this paper. The coverage area of the vegetation based on MSAVI2 was $7,833.0 \mathrm{~km}^{2}$, accounting (34.7\%) of the total study area. Table 3 shows the vegetation density classes and the area of each class. It was clear that the dense vegetation cover is concentrated in the Northwestern part of the study area, while poor and sparse vegetation are located in the middle and Southeastern parts.

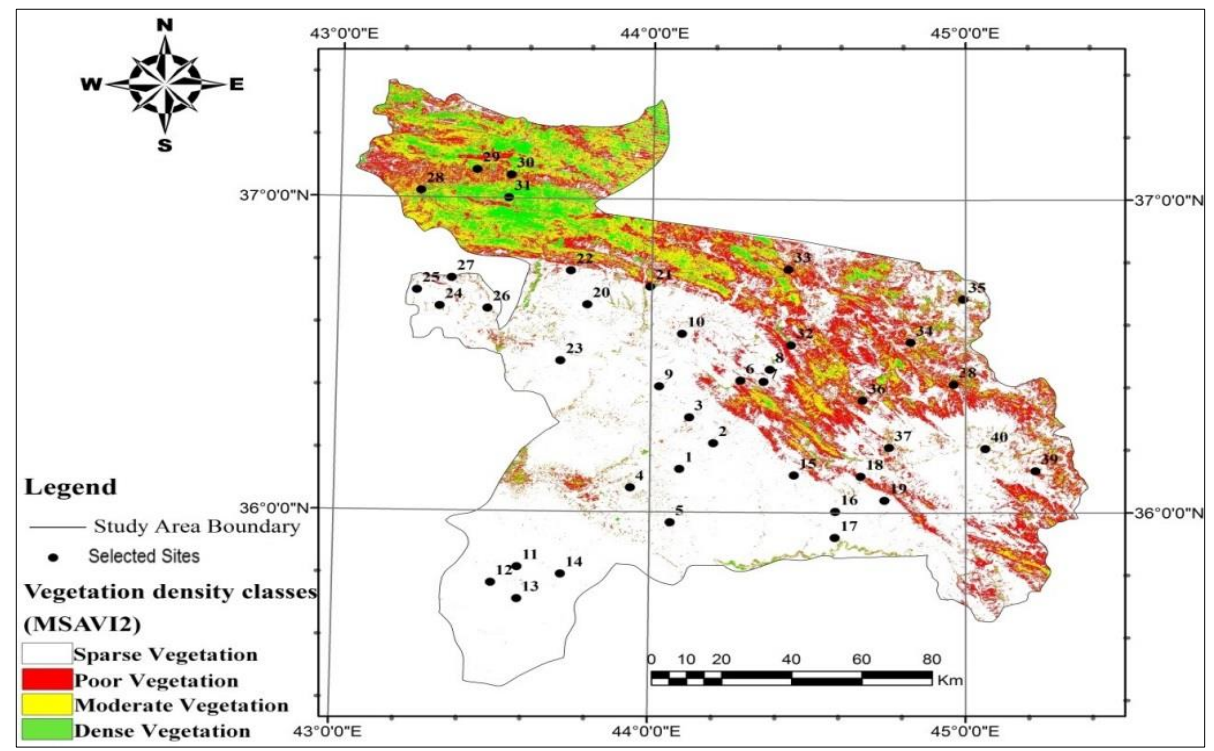

Figure 6. The MSAVI2-based vegetation cover density classes in the study area.

\subsubsection{5. $T C G$}

The TCG is a greenness indicator of the tasseled cap transformation, which is utilized in this study for vegetation cover extraction in the IKR. The total area of vegetation cover based on the TCG (Figure 7 and Table 3 was 5,976.7 $\mathrm{km}^{2}$, accounting (26.5\%). This index detected almost the same vegetation density spatial distribution pattern. Poor vegetation was found spreads in the Eastern part, and more sparse vegetation exists in the Southern and Southeastern parts.

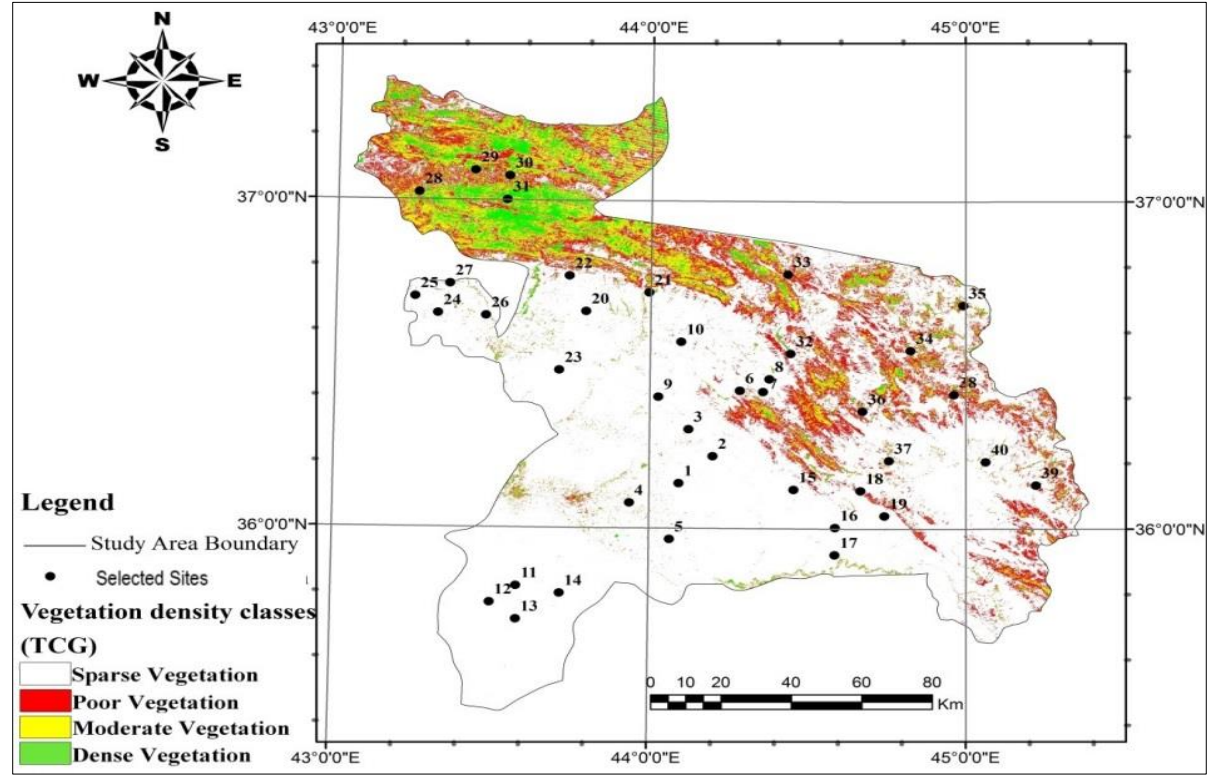

Figure 7. The TCG-based vegetation cover density classes in the study area. 
Table 3. The vegetation cover area detected by the vegetation indices in 2012

\begin{tabular}{|c|c|c|c|c|c|c|c|c|c|c|}
\hline Vegetation & NDVI & NDVI & SAVI & SAVI & OSAVI & OSAVI & MSAVI2 & MSAVI2 & TCG & TCG \\
\hline Density class & $\mathrm{km}^{2}$ & $\%$ & $\mathrm{~km}^{2}$ & $\%$ & $\mathrm{~km}^{2}$ & $\%$ & $\mathrm{~km}^{2}$ & $\%$ & $\mathrm{~km}^{2}$ & $\%$ \\
\hline Low Dense & $4,368.2$ & 54.1 & $1,675.5$ & 51.6 & $4,872.8$ & 52.4 & $3,998.7$ & 51.0 & $2,924.0$ & 48.9 \\
\hline Moderate Dense & $2,554.9$ & 31.6 & $1,170.7$ & 36.1 & $2,998.5$ & 32.3 & $2,623.3$ & 33.5 & $2,149.0$ & 36.0 \\
\hline High Dense & $1,156.8$ & 14.3 & 400.9 & 12.3 & $1,425.2$ & 15.3 & $1,210.9$ & 15.5 & 903.7 & 15.1 \\
\hline Total & $8,079.9$ & 100 & $3,247.1$ & 100 & $9,296.7$ & 100 & $7,833.0$ & 100 & $5,976.7$ & 100 \\
\hline$\%$ & & 35.8 & & 14.4 & & 41.2 & & 34.7 & & 26.5 \\
\hline
\end{tabular}

\subsection{DEM}

Most studies that employed remote sensing data were concentrated on two-dimensional horizontal patterns. Only a few ones focused on effect of elevation on the vertical distribution of vegetation in mountainous areas (Franklin, 1995; Edwards et al., 1996; Guisan and Zimmermann, 2000; Hansen et al., 2000; and Miller et al., 2004). The current study attempted to investigate both the vertical and horizontal vegetation distribution in the study area. Elevation had a significant role in this approach by affecting several variables influencing the vegetation growth. For this reason, maps of TIN, aspect, and slope (Figures 8-10) were achieved utilizing the DEM dataset to investigate their statistical relations with the spectral vegetation and soil indices. The study results showed that the topography variable is the most influencing vegetation growth (Table 4).

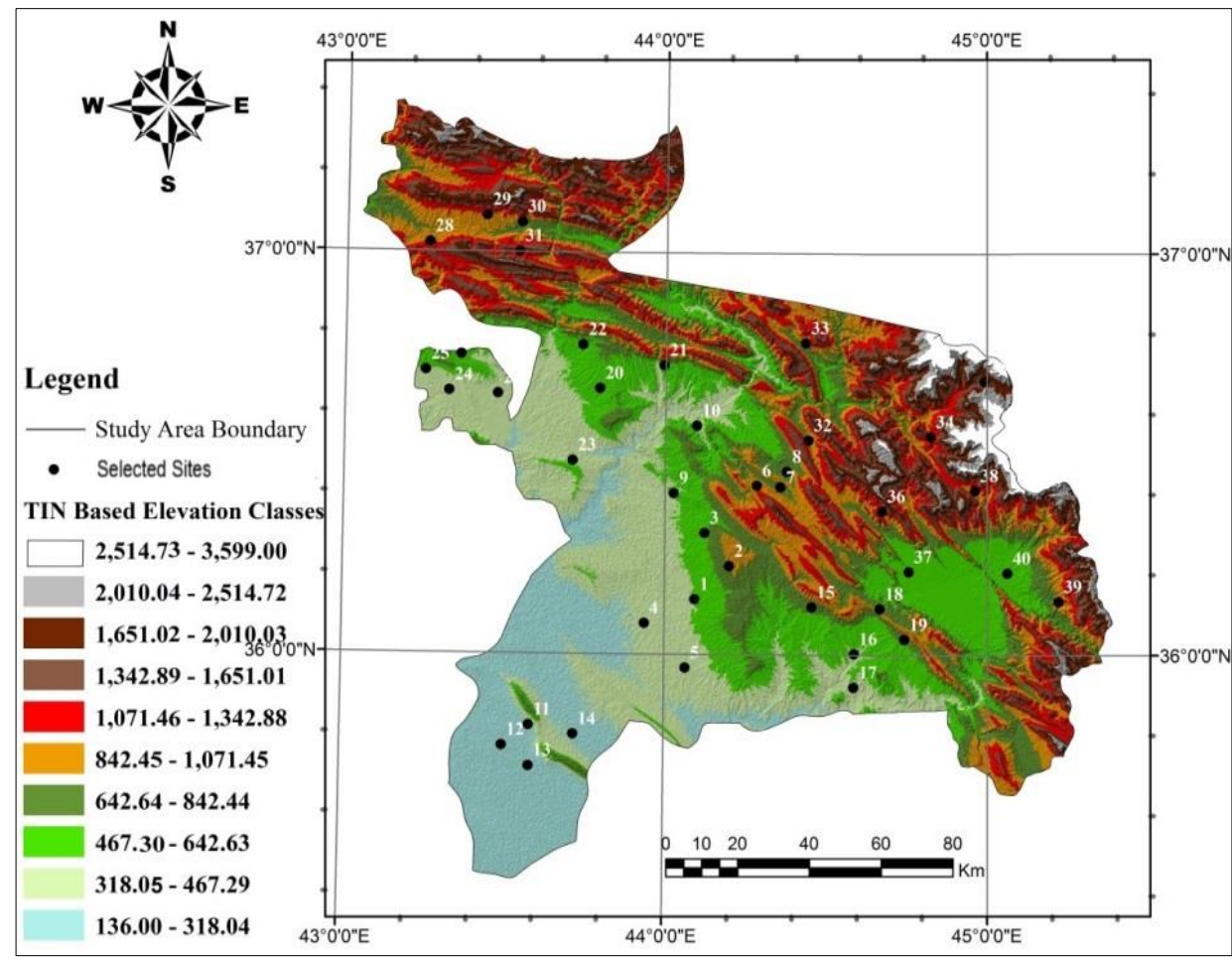

Figure 8 The TIN map of the study area. 


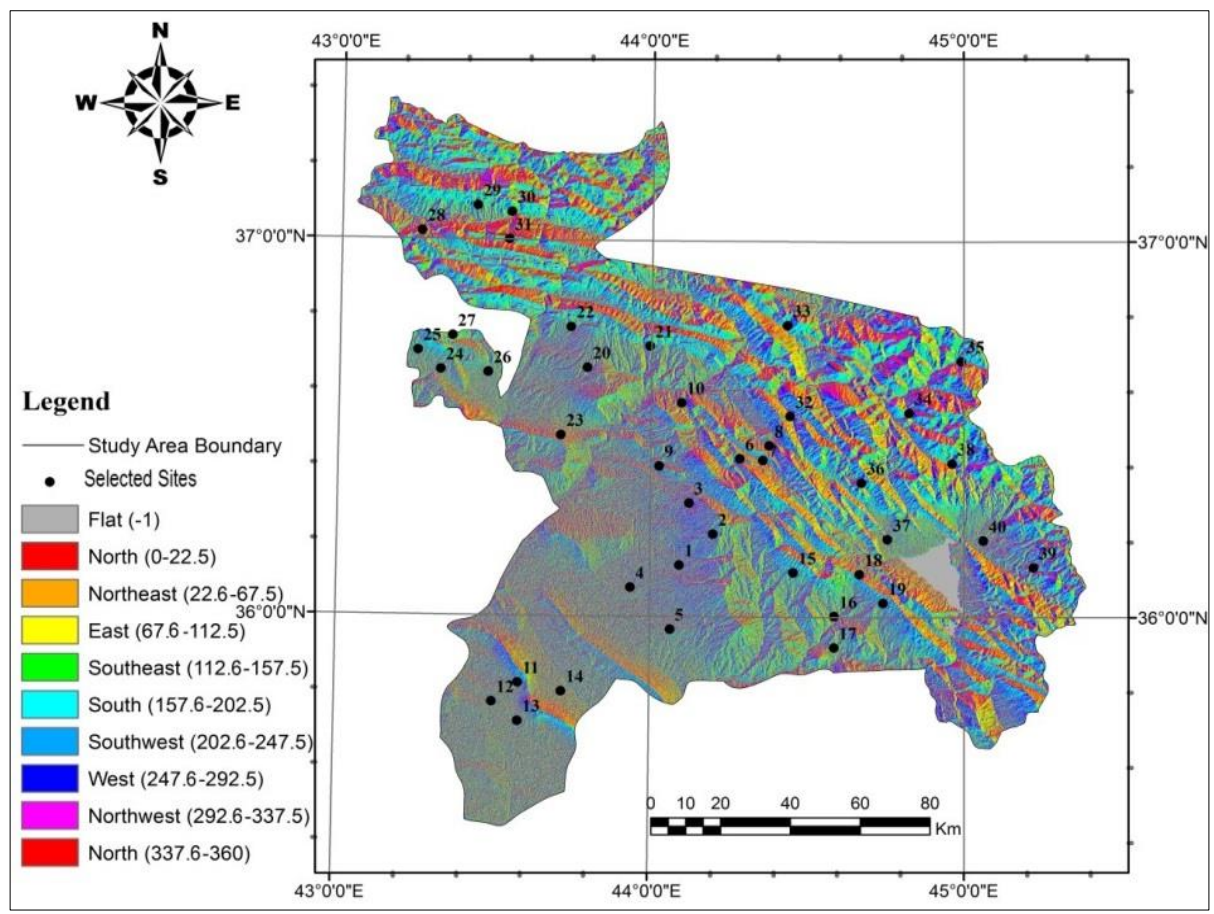

Figure 9 The Aspect ratio map of the study area.

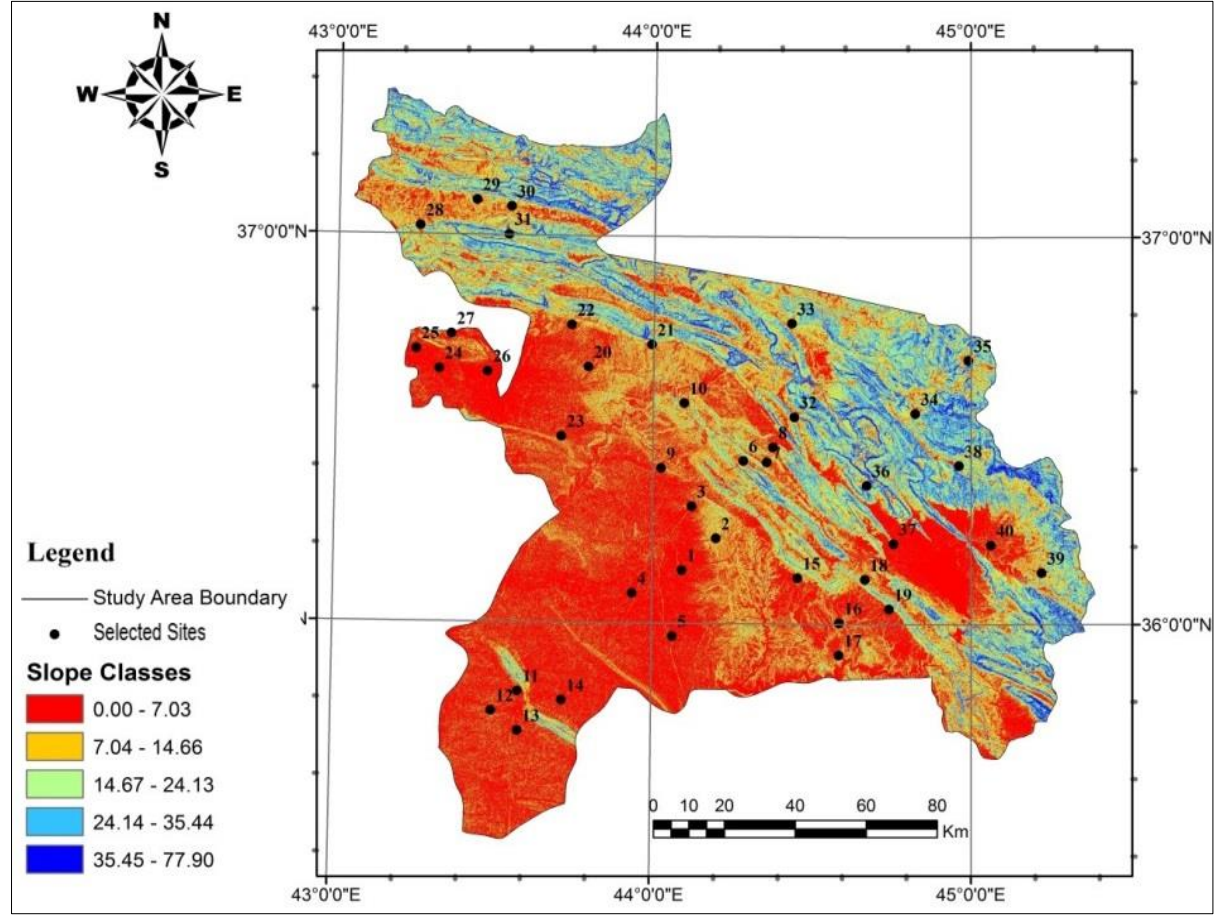

Figure 10 The slope map of the study area.

\subsection{Statistical Analysis}

\subsection{1. $\quad$ Statistical Correlations Among the Studied Indices and DEM}

Table 4 shows statistical correlations among the vegetation indices, LST, and the DEM. The results revealed significant positive correlations among the DEM, and each of the vegetation indices, while a significant 
negative relationship is found between the LST and each vegetation indices. These results indicate that an increase in elevation causes a decrease in LST then an increase in soil moisture content, leading to an increase in vegetation cover. LST decreases with elevation increasing occurred at a fairly uniform rate of about $6.4^{\circ} \mathrm{C} / \mathrm{km}$ (Glickman, 2000). Also, the DEM had a significant negative correlation with LST by (0.575). On the other hand, it is found significant positive correlations among MSAVI2 and each of TCG, SAVI, NDVI, and OSAVI. In areas where vegetation is dense, the LST never rises above $35{ }^{\circ} \mathrm{C}$. NASA, 2014 reported that the hottest land surface temperatures on the Earth are in deserts and bare lands.

Table 4. The correlation coefficients values among studied indices and the dem

\begin{tabular}{|c|c|c|c|c|c|c|c|}
\hline & DEM & MSAVI2 & TCG & SAVI & NDVI & LST & OSAVI \\
\hline DEM & & $0.577(* *)$ & $0.775(* *)$ & $0.728(* *)$ & $0.728(* *)$ & $-0.575(* *)$ & $0.574(* *)$ \\
\hline MSAVI2 & & & $0.748(* *)$ & $0.770(* *)$ & $0.760(* *)$ & $-0.470(* *)$ & $0.857(* *)$ \\
\hline TCG & & & & $0.937(* *)$ & $0.932(* *)$ & $-0.397(*)$ & $0.686(* *)$ \\
\hline SAVI & & & & & $0.995(* *)$ & $-0.487(* *)$ & $0.685(* *)$ \\
\hline NDVI & & & & & & $-0.494(* *)$ & $0.671(* *)$ \\
\hline LST & & & & & & & $0.450(* *)$ \\
\hline
\end{tabular}

\section{Discussion}

The study results pointed out that the dense and moderate dense vegetation classes are spread out in the Northwestern part of the study area. At the same time, they gradually decreased toward the Southeast and the Southwest parts. This shrinkage in the vegetation density can be ascribed to the unfavorable climatic conditions for vegetation growth in the study area. From the rain point of view, the increase in rain averages encourages vegetation growth, leads to vegetation density increase. This result was also is stated by Hashemi, (2011).

Moreover, based on the TIN maps (Figure 8), it is noticed that the elevation decreasing coincide with the reduction of the vegetation cover density. The mountainous terrain is characterized by high elevation (around 2,000 meters above sea level). Generally, the mountains in the IKR, are characterized by their great heights in the North and Northeastern parts, while their heights gradually decrease towards the South and Southwest. Statistical analysis results showed significant positive correlations between the DEM values (elevations) and all vegetation indices. In more detail, LST appeared negative correlations with DEM, TCW, and all studied vegetation indices. This trend explains that an increase in elevation causes a decrease in land surface temperature, which subsequently causes a rise in soil/vegetation moisture and offer a suitable local environment for vegetation growth.

All vegetation indices had been significantly responded to the aspect ratio variations. The results revealed that densest vegetation is spread in the sites between 180 to $350^{\circ}$. In detail, it is located in the South (157.5$\left.202.5^{\circ}\right)$, Southwest $\left(202.5-247.5^{\circ}\right)$, West $\left(247.5-292.5^{\circ}\right)$, Northwest (292.5-337.5), and North $\left(337.5-360^{\circ}\right)$ as presented in Figure 9. The results also showed that MSAVI2 was the most vegetation index highly responded to the aspect ratio than the other vegetation indices, whereas MSAVI2-based vegetative cover extends between $340^{\circ}$ Northwest and $70^{\circ}$ Northeast, as reported in (Jin et al., 2008). The aspect ratio results disclosed that the maximum growth of the vegetation cover was at the shaded side of the mountains in the study area more than the sunny side, whereas more dense vegetation cover is noticed on the shady side.

On the contrary, much less evapotranspiration process is expected, which is essential for vegetation growth, is mainly noticed when the mountains are located in a semi-arid region (Jin et al., 2008). Slope of the study area was characterized by more variation (Figure 10), whereas more dense vegetation cover is detected at 
slope $9-17^{\circ}$ in the mountainous area. Also, MSAVI2 was the most index reacted to the slope and the aspect ratio.

In terms of LST (Figure 2), it is evident that the vegetation cover presence is negatively related to the LST. Whereas from the Northeast to the Southwest direction, the LST increase was obvious, concomitant with diminishing vegetation cover. Several environmental factors control vegetation cover growth and its spatial distribution, such as topographical factors and their influence on climate conditions (Daubenmire, 1954). Statistically, the results revealed a significant negative correlation between LST values and all vegetation indices, as previously mentioned in this paper. Gillies et al. (1997) stated that the relationship between soil moisture, NDVI, and LST could be called a "Universal Triangle". Furthermore, elevation, aspect, and slope are three main topographic factors that control vegetative cover distribution in mountainous areas (Gillies, 1997). Among these three factors, elevation is the most crucial factor (Day \& Monk, 1974; Busing et al., 1992).

Among all vegetation indices utilized in the current study, the OSAVI (Table 3) has detected the higher vegetative area in the study area, which revealed that it is more sensitive to vegetation than the other indices. Nevertheless, MSAVI2 was the most reliable and efficient vegetation index in detecting the sparse vegetation. Validation of the study results is proved the capabilities of the studied vegetation indices in mapping vegetation presence and vegetation vitality in different sites of the study area. Moreover, our study results revealed that the MSAVI2 was the most vegetation index associated with aspect ratio and slope changing. Li et al. (2013) also considered MSAVI2 as the most efficient vegetation index, whereas it is designed to reduce the influence of soil in the image and to enhance the spectral sensitivity for concentrated vegetation.

\section{Conclusions}

In this paper, we investigated and compared performance of five spectral vegetation indices in the study area located in the IKR. The results revealed that MSAVI2 could be considered a reliable vegetation index, which can be efficiently utilized to explore the vitality and existence of vegetative cover in the semi-arid lands. This consideration is concluded due to its capabilities in sensing the sparse vegetation cover and canceling the noises from non-vegetated features in which the current study has been validated in situ. Besides, the results revealed that dense vegetation is spreading in the Northwest part of the study area and gradually decreasing toward the South and Southeastern parts. Vegetation shrinkage could be ascribed to decreasing in elevation and rain amounts associating with an increase in land surface temperature.

Furthermore, dense vegetation cover is found on the shady sides of the study area's mountains more than the sunny side. On the contrary, this study is concluded that slope has a significant role in vegetation distribution. Moreover, areas with slopes around $10^{\circ}$ appeared the best one to retain rainwater in the soil, and eventually, increase soil moisture necessary for vegetation growth in the mountainous area. An elevation increase could reduce surface temperature associated with rain amounts increase, which consequently offers suitable conditions for dense vegetation growth and existence. However, this study results could support future work to incorporate soil properties field measurements, and satellite time series dataset for more detailed investigation on this topic.

\section{References}

Al-Quraishi, A.M.F., Sadiq, H.A., and Messina, J.P. (2019). Characterization and Modeling Surface Soil Physicochemical Properties Using Landsat Images: A Case Study in the Iraqi Kurdistan Region. The Munich remote Sensing Symposium (MRSS19), Munich, Germany 18-20 Sep.. ISPRS Archives. (2019b) https://doi.org/10.5194/isprs-archives-XLII-2-W1621-2019. 
Al-Quraishi, A.M.F., and Negm, A.M. (2020). Environmental Remote Sensing and GIS in Iraq. Springer-Water, Springer, Cham. ISBN: 978-3-030-21343-5.

Al-Quraishi, A.M.F., Qader, S.H., and Wu, W. (2020). Drought Monitoring Using Spectral and Meteorological Based Indices Combination: A Case Study in Sulaimaniyah, Kurdistan Region of Iraq. In: Al-Quraishi, A. M. F., \& Negm, A. M. (eds). Environmental Remote Sensing and GIS in Iraq. Springer-Water, Springer, Cham. https://doi.org/10.1007/978-3-03021344-2_15

Anonymous, (2003). United Nations Environment Programme (UNEP), availableat http://sea.unepwcmc.org/latenews/Iraq_2003/facts.htm accessed on 2014.

Anonymous, (2014). Kurdistan's geography and climate, available at official Kurdistan regional government page at http://www.krg.org/p/page.aspx?l=12\&s=050000\&r=303\&p=213 Accessed on 2014.

Aziz, M. (2003). Agrometeorology in Kurdistan of Iraq: a contemporary history:http://www.agrometeorology.org/topics/historyof agrometeorology/agrometeorology-in-kurdistan-of-iraq-a-contemporary-history accessed on 2014.

Babbie, ERR (2009). The Practice of Social Research. 12th edition, Wadsworth Publishing, 2009, ISBN 0-495-59841-0, pp. 436440.

Busing, R.T., White, P.S., and MacKende, M.D. (1992). Gradient analysis of old spruce-fir forest of the Great Smokey Mountains circa 1935. Canadian Journal of Botany, 71, 951-958.

Chrisman, N.R. (2002). Exploring geographic information systems. J. Wiley and Sons, New York.

Crimmins, T.M., Crimmins, M.A., and Bertelsen, C.D. (2009). Flowering range changes across an elevation gradient in response to warming summer temperatures. Glob. Change Biol. 15 1141-52.

Crimmins, T.M., Crimmins, M.A., and Bertelsen, C.D. (2010). Complex responses to climate drivers in onset of spring flowering across a semi-arid elevation gradient. J. Ecol. 98 1042-51.

Daubenmire, R.F. (1954).Alpine timberlines in the Americas and their interpretations. Butler univ.bot.stud.11:119-136.

Day, FPP, and Monk, C.D.D. (1974). Vegetation patterns on a Southern Appalachian watershed. Ecology, 55, 1064-1074.

Dissing, D., and D. L. Verbyla (2003), Spatial patterns of lightning strikes in interior Alaska and their relations to elevation and vegetation, Can. J. For. Res., 33, $770-782$.

Edwards, G.R., Parsons, A.J., Newman, J.A., and Wright, I.A. (1996). The spatial pattern of vegetation in cut and grazed grass/white clover pastures. Grass and Forage Science, 51, 219-231.

Fadhil, A.M. (2009). Land Degradation Detection Using Geo-Information Technology for Some Sites in Iraq. Journal of AlNahrain University Science 12, 3, 94-108. DOI: https://doi.org/10.22401/JNUS.12.3.13

Fadhil, A.M. (2011). Drought mapping using Geoinformation technology for some sites in the Iraqi Kurdistan region. International Journal of Digital Earth, 4(3), 239-257. DOI: https://doi.org/10.1080/17538947.2010.489971

Fadhil, A.M. (2013). Sand dunes monitoring using remote sensing and GIS techniques for some sites in Iraq. In The $3 r d$ International Conference on Photonics and Image in Agriculture Engineering (PIAGENG 2013), Jan. 27-28. DOI: https://doi.org/10.1117/12.2019735

Franklin, J. (1995). Predictive vegetation mapping: geographic modeling of biospatial patterns in relation to environmental gradients. Progress in Physical Geography, 19, 474-499.

Gaznayee, H. A. A. ., Al-Quraishi, A. M. F. (2019a) 'Analysis of agricultural drought, rainfall, and crop yield relationships in erbil province, the kurdistan region of iraq based on landsat time-series msavi2', Journal of Advanced Research in Dynamical and Control Systems, 11(12 Special Issue), pp. 536-545. doi: https://doi.org/10.5373/JARDCS/V11SP12/20193249.

Gaznayee, H. A. A. ., Al-Quraishi, A. M. F (2019b) 'Analysis of Agricultural Drought' s Severity and Impacts in Erbil Province, the Iraqi Kurdistan Region based on Time Series NDVI and TCI Indices for 1998 through 2017', Jour of Adv Research in Dynamical \& Control Systems, 11(11), pp. 287-297. doi: https://doi.org/10.5373/JARDCS/V11I11/20193198.

Gaznayee, H. A. A. ., Al-Quraishi, A. M. F (2020) 'Identifying Drought Status in Duhok Governorate ( Iraqi Kurdistan Region ) from 1998 through 2012 using Landsat Time Series Dataset', Journal of Applied Science and Technology Trends, 01(01), pp. 17-23. doi: https://doi.org/10.38094/jastt1112.

Gibson, P.J. (2000). Remote Sensing: Principles and Concepts. Taylor and Francis Group, London, U.K. Schurrman, N. (2004). GIS - a short introduction. Blackwell, Oxford. p:127.

Gillies, R.R., Carlson, T.N., Cui, J., Kustas, W.P., and Humes, K.S. (1997). A verification of the 'triangle' method for obtaining surface soil Water content and energy fluxes from remote measurements of the Normalized Difference Vegetation index (NDVI) and surface radiant temperature. International Journal of Remote Sensing, 18, 3145 - 3166.

Gitlin, A.R., Shultz, C.M., Bowker, M.A., Stumpf, S., Paxton, K.L., Kennedy, K., Munoz, A., Bailey, J.K., and Whitham, T.G. (2006). Mortality gradients within and among dominant plant populations as barometers of ecosystem change during extreme drought. Conservation Biol. 20 1477-86.

Glickman, T.S. (2000). Glossary of Meteorology (2nded.). American Meteorological Society, Boston. ISBN 1-878220-34-9. (Glossary of Meteorology). 
Guisan, A., and Zimmermann, N. (2000). On the use of static distribution models in Ecology. Ecological Modelling, 135, 147186.

Haboudane, D., John, R., Millera, J.R., Tremblay, N., Zarco Tejada, P.J., and Dextraze, L. (2002). Integrated narrow-band vegetation indices for prediction of crop chlorophyll content for application to precision agriculture. Remote Sens. Environ. 81, 416-426.

Hansen, A.J., Rotella, J.J., Kraska, M.P.V., and Brown, D. (2000). Spatial patterns of primary productivity in the Greater Yellowstone Ecosystem. Landscape Ecolog, 15, 505-522.

Harris, N.R., Louhaichi, M., and Johnson, D.E. (2004). Laboratory Manual for Landscape Ecology, Spatial Analysis of Landscape Data, Lab 9, Landscape Ecology and Analysis. URL: http://www.oregonstate.edu/dept/range/labmanual/Laboratory9.pdf.

Hashemi, S.A. (2011). Investigation of Relationship Between Rainfall and Vegetation Index by Using NOAA/AVHRR Satellite Images. Department of Forestry, Lahijan Branch, Islamic Azad University, Lahijan, Iran, World Applied Sciences Journal 14 (11): 1678-1682, 2011, ISSN 1818-4952.

Herrmann, S.M., Didan, K., Barreto-Munoz, A., and Crimmins, M.A. (2016). Divergent responses of vegetation cover in Southwestern US ecosystems to dry and wet years at different elevations. Environmental Research Letters, Volume 11, Number 12.

Huete, A.R. (1988). A soil-adjusted vegetation index (SAVI). Remote Sensing of Environment. 25, 295 - 309.

Izady, M.R. (1992). The Kurds. A Concise Handbook, Dep. of Near Easter Languages and Civilazation, Harvard University, USA.

Jensen, J.R. (1996). Introductory Digital Image Processing: A Remote Sensing Perspective. 2nd Edition. New Jersey, USA: Prentice Hall. p:133-135

Jin, X.M., Zhang, Y.K., Schaepman, M.E., Clevers, JGPGPW, and Su, Z. (2008). Impact of elevation and aspect on the spatial distribution of vegetation in the Qilian mountain area with remote sensing data. The International Archives of the Photogrammetry, Remote Sensing and Spatial Information Sciences, XXXVII. Part B7. Beijing 2008.

Jolly, W.M., Dobbertin, M., Zimmermann, N.E., and Reichstein, M. (2005). Divergent vegetation growth responses to the 2003 heat wave in the Swiss AlpsGeophys. Res. Lett. 32 L18409.

Justice C., Vermote E., Townshend, J.R.G., Defries, R., Roy, D.P., Hall, D.K., Salomonson, V.V., Privette, J., Riggs, G., Strahler, A., Lucht, W., Myneni, R., Knjazihhin, Y., Running, S., Nemani, R., Wan, Z., Huete, A.R., Vanleeuwen, W., Wolfe, R., Giglio, L., Muller, J.P., Lewis, P., and Barnsley, M. (1998). The Moderate Resolution Imaging Spectroradiometer (MODIS): Land remote sensing for global change research, IEEE Trans. Geosci. Remote Sensing, 36: 1228-1249.

Kauth, R.J. and Thomas, G.S. (1976). The tasseled cap - a graphic description of the spectral temporal development of agricultural crops as seen in Landsat, Proceedings of the Symposium on Machine Processing of Remotely Sensed Data, Purdue University of West Lafayette, Indiana, 1976, pp. 4B-41 to 4B-51.

Kelly A E and Goulden M L 2008 Rapid shifts in plant distribution with recent climate change Proc. Natl Acad. Sci. USA 105 11823-6.

Kilinc, M., and Beringer, J. (2007). The spatial and temporal distribution of lightning strikes and their relationship with vegetation type, elevation, and fire sears in the Northern Territory. Journal of Climate, 20(7), 11611173. https://doi.org/10.1175/JCLI4039.1

Kotroni, V., \& Lagouvardos, K. (2008). Lightning occurrence in relation with elevation, terrain slope, and vegetation cover in the Mediterranean. J. Geophys. Res., 113, D21118, doi: https://doi.org/10.1029/2008JD010605.

Leonelli, G., Pelfini, M., di Cella, U.M., and Garavaglia, V. (2011). Climate warming and the recent treeline shift in the european alps: the role of geomorphological factors in high-altitude sites. Ambio 40 264-73.

Li, X.B., Long, H.L., and Wang, H. (2013). Vegetation cover estimation based on in-suit hyperspectral data: a case study for meadow steppe vegetation in inner Mongolia. China. Int. J. Agric. Biol., 15: 285-290.

Miller, J.R., Turner, M.G., Stanley, E.H., Smithwick, E.A.H., and Dent, L.C. (2004). Spatial extrapolation: the science of predicting ecological patterns and processes. Bioscience, 54, 310-320.

Mohan, M. (2000) "Climate change: evaluation of ecological restoration of delhi ridge using remote sensing and GIS technologies," International Archives of Photogrammetry and Remote Sensing, 33, pp. 886-894.

NASA. (2014). Land Surface Temperature \& Vegetation. Available online athttp://earthobservatory.nasa.gov/GlobalMaps/view.php?d1=MOD11C1_M_LSTDA\&d2=MOD13A2_M_NDVI accessed on 2014.

NRC. (2007). Earth Science and Applications from Space: National Imperatives for the Next Decade and Beyond, National Research Council of the National Academies, The National Academies Press, Washington, DC, p.428. URL:http://www.nap.edu/openbook.php?record_id=11820\&page $=428$.

Piao, S.L., Cui, M.D., Chen, A.P., Wang, X.H., Ciais, P., Liu, J. and Tang, Y.H. (2011). Altitude and temperature dependence of change in the spring vegetation green-up date from 1982 to 2006 in the Qinghai-Xizang Plateau. Agric. Forest Meteorol. 151 1599-608. 
Qi, J., Chehbouni, A., Huete, A.R., Kerr, Y.H., and Sorooshian, S. (1994a). A modified soil adjusted vegetation index. Remote Sensing of Environment, 48, pp. 119-126.

Qi, J., Kerr, Y., and Chehbouni, A. (1994b).External factor consideration in vegetation index development. Proc. of Physical Measurements and Signatures in Remote Sensing, ISPRS, 723-730.

Rondeaux, G., Steven, M., and Baret, F. (1996). Optimization of soil-adjusted vegetation indices, Remote Sensing of Environment, 55, $95-107$.

Rouse, J.W., Haas, R.H., Schell, J. A., and Deering, D.W. (1973). Monitoring Vegetation Systems in the Great Plains with ERTS, Third ERTS Symposium. NASA SP-351 I, 309- 317.

YCEO (The Yale University Center for Earth Observation). (2010) - Converting Landsat TM and ETM+ thermal bands to temperature. Available at: http://www.yale.edu/ceo/Documentation/Landsat_DN_to_Kelvin.pdf (last accessed: $11 / 10 / 2012)$. 